\title{
Porównanie zgodności diagnozy funkcjonalnej wg McKenziego pacjentów z dolegliwościami odcinka lędźwiowego kręgosłupa pomiędzy - instruktorem metody, a fizjoterapeutą po kursie A
}

\section{Inter-rater reliability of McKenzie functional diagnosis of low back pain patients between - the instructor and physiotherapist after A course}

Agnieszka Morko, Aleksandra Truszczyńska, Dorota Reszelewska

Akademia Wychowania Fizycznego w Warszawie, Wydział Rehabilitacji, Katedra Fizjoterapii

\section{Streszczenie}

Wstęp: Zespoły bólowe odcinka lędźwiowego kręgosłupa są powszechnym problemem współczesnych społeczeństw. Rzetelna diagnoza funkcjonalna jest kluczem do postawienia rozpoznania oraz stanowi pierwszy etap do rozpoczęcia leczenia tego schorzenia oraz zapobiegania jego nawrotom. Celem pracy było zbadanie zgodności stawianej diagnozy przez początkującego terapeutę po ukończeniu kursu ,A” według metody McKenziego w porównaniu $\mathrm{z}$ diagnozą stawianą przez instruktora metody $\mathrm{z}$ wieloletnim doświadczeniem.

Materiat $i$ metody: Badania były prowadzone w Instytucie McKenziego Polska w Poznaniu. Pacjentami $(\mathrm{n}=30)$ z bólami odcinka lędźwiowego kręgosłupa poddani zostali diagnostyce metodą McKenziego. Analizie poddano następujące elementy diagnozy i leczenia: rozpoznanie, kierunkową preferencję ruchu, wybór pozycji wyjściowej do ćwiczeń oraz ich częstotliwość.

Wyniki: Na podstawie przeprowadzonych badań stwierdzono zgodność diagnoz na poziomie: $75 \%$, 100\%, 100\% i 78\% odpowiednio dla zmiennych: rozpoznanie, kierunek leczniczy, pozycja wyjściowa i częstotliwość ćwiczeń.

Wnioski:

1. Kurs „A” metody McKenziego, jako pierwszy etap szkolenia pozwala w pełni przygotować terapeutę do zadań takich jak diagnostyka i planowanie terapii pacjentów z dolegliwościami bólowymi kręgosłupa lędźwiowego.

2. Metoda McKenziego umożliwiła minimalizację błędów diagnostycznych, pomimo dużej różnicy w doświadczeniu diagnostów.

3. Różnice wynikające $\mathrm{z}$ doświadczenia diagnostów istniały przede wszystkim w sytuacjach diagnozowania pacjentów kwalifikujących się do grupy „,inne”.

Słowa kluczowe:

ból odcinka lędźwiowego kręgosłupa, diagnostyka metodą McKenziego, instruktor metody McKenziego, trafność diagnozy 


\section{Abstract}

Introduction: Low back pain is a common problem of modern society. Reliable functional diagnosis is the key to diagnosis and is the first step in treating this disease and to prevent its recurrence.

The aim of the study was to examine the inter- rater reliability of diagnosis by a novice therapist after completing the course " $\mathrm{A}$ " of the McKenzie method compared with the diagnosis made by the experienced instructor.

Material and methods: The study was conducted at the Institute McKenzie Poland in Poznan. Patients $(n=30)$ of the low back pain were diagnosed by McKenzie method. Following variables were analyzed: diagnosis, directional, starting position for the exercise and their frequency.

Results: Following inter-rater reliability was found for Kappa coefficient: diagnosis 0.75 , therapeutic direction 1.0, starting position 1.0 and frequency of exercise 0.78 .

Conclusions:

1. Course "A" of McKenzie method can fully prepare the therapist for tasks such as diagnosis and treatment planning of patients with low back pain.

2. McKenzie method allowed to minimize diagnostic errors, despite the large difference in the experience of diagnosticians.

3. Differences arising from the experience of diagnosticians were primarily in situations diagnose patients eligible for "other".

Key words:

lumbar spine pain, diagnosis and therapy of McKenzie method, instructor of McKenzie method, accuracy of diagnosis

\section{Wstęp}

Występowanie bólów odcinka lędźwiowego - kręgosłupa jest bardzo powszechne. W Wielkiej Brytanii zespoły bólowe kręgosłupa dotykają ok. $60 \%$ populacji [1]. Ostre epizody bólowe kręgosłupa stanowią drugą co do częstości przyczynę interwencji pogotowia ratunkowego w Stanach Zjednoczonych, co stanowi 3,15\% wszystkich wezwań notowanych w tym kraju [2]. Dla porównania w Polsce na dolegliwości bólowe odcinka lędźwiowego kręgosłupa cierpi już co czwarta kobieta i co piąty mężczyzna powyżej 15 roku życia [3].

Dolegliwości bólowe dotykają osób w wieku dorosłym jak również dzieci i młodzież [4,5]. U osób pracujących są one często związane z czynnikami dotyczącymi ich pracy zawodowej [6,7]. Natomiast, jak podaje Hasler „u osób w młodszym wieku dolegliwości bólowe często mają związek z czynnikami rozwojowymi takimi jak: wady postawy i choroby wrodzone jak np. choroba Sheuermanna" [8]. Styl życia dziecka też nie pozostaje bez znaczenia. Zarówno długotrwałe obciążenie statyczne oraz zła kondycja fizyczna mogą być tak samo szkodliwe jak nadmiar aktywności fizycznej. Warto również wspomnieć, że im młodszy wiek pacjenta tym większe ryzyko, iż dolegliwości bólowe mają swoją przyczynę w poważnej patologii takiej jak: nowotwór czy zapalenie. Według Haslera ,ryzyko poważnego schorzenia u pacjentów poniżej 5 roku życia wynosi aż 50\%" [9,10].
Biorąc pod uwagę powyższe rozważania widoczne staje się, jak powszechny i wieloaspektowy problem stanowią dolegliwości bólowe pochodzące z kręgosłupa. Przestają być one wyłącznie problemem klinicznym, a stają również się społecznym, ponieważ narażają społeczeństwo na wysokie koszty leczenia jak również odszkodowań i wypłat $\mathrm{z}$ tytułu rent.

Diagnostyka i terapia metodą McKenziego jest odpowiedzią na problemy dużej grupy pacjentów z dolegliwościami bólowymi kręgosłupa. Jej autor wyróżnił trzy niespecyficzne zespoły mechaniczne: posturalny, dysfunkcyjny oraz zespół zaburzeń strukturalnych tzw. derangement. Aby lepiej zrozumieć tą klasyfikację musimy najpierw przyjrzeć się definicji zespołu mechanicznego. Według McKenziego „opisuje on jednostkę chorobową rozpoznawalną na podstawie typowego wzorca objawów, które można wykorzystywać również, jako wskazówki podczas leczenia, ponieważ zespół opisuje także odróżnialny wzorzec reakcji." Autor zaznacza również, iż rozpoznanie zespołu następuje podczas oceny mechanicznej, co rozumiemy przez ukierunkowany i szczegółowy wywiad oraz badanie przedmiotowe. Po wspomnianym przez autora wywiadzie stosujemy strategię obciążeń, statycznych jak również dynamicznych, które zależnie od wywołanego efektu pomogą nam sklasyfikować pacjenta do jednego z wyżej wymienionych zespołów [11]. Z założenia metoda McKenziego uczy również pacjenta radzenia sobie na co dzień $z$ jego do- 
legliwościami. W efekcie pozwala to na zmniejszenie kosztów leczenia wymienionych wyżej jako problem społeczny. Nasuwa się jednak pytanie, na ile powtarzalna jest trafność stawianej diagnozy i proponowanej terapii w zależności od etapu kształcenia i doświadczenia terapeuty.

\section{Cel pracy}

Celem pracy było określenie zgodności diagnozy stawianej przez terapeutę, który ukończył kurs „A” metody McKenziego oraz instruktora $-\mathrm{z}$ wieloletnim doświadczeniem.

\section{Pytania badawcze}

1. Czy kurs „A” metody McKenziego potrafi w sposób rzetelny przygotować terapeutę do zadania, jakim jest diagnostyka i planowanie terapii pacjentów z dolegliwościami bólowymi odcinka lędźwiowego kręgosłupa?

2. Czy metoda McKenziego zapewnia zminimalizowanie błędów diagnostycznych pomimo różnicy w doświadczeniu zawodowym diagnostów?

3. Czy metoda McKenziego jest w stanie zaproponować uniwersalny algorytm diagnostyczny skuteczny niezależnie od poziomu wiedzy i umiejętności terapeuty?

\section{Materiały i metody}

Badanie zostało przeprowadzone na grupie 30 pacjentów (12 kobiet i 18 mężczyzn) w wieku od 21 do 88 lat (średnia wieku 50,3). Pacjenci zgłosili się do Kliniki McKenziego w Poznaniu z bólami odcinka lędźwiowego kręgosłupa. Badania przeprowadzono podczas pierwszej wizyty. Wszyscy pacjenci wyrazili zgodę na udział $\mathrm{w}$ badaniu.

Kryteria włączenie do badań: pierwsza wizyta diagnostyczna, bóle odcinka lędźwiowego kręgosłupa.

Kryteria wyłączenia: diagnozowanie i leczenie metoda McKenziego w przeszłości, pacjenci z bólami odcinka szyjnego, piersiowego oraz kończyn, pochodzące $\mathrm{w}$ innych stawów obwodowych, objawy wymagające pilnej konsultacji specjalistycznej, bóle spowodowane urazami, obciążenia układu krążenia i oddechowego wykluczające uczestniczenie w aktywnej formie fizjoterapii.

Pacjenci byli badani przez instruktora, któremu towarzyszył terapeuta po kursie „A”, pełniący rolę obserwatora. Instruktor był lekarzem ortopedą, specjalista rehabilitacji medycznej z 35 letnim doświadczeniem klinicznym. Fizjoterapeuta był po licencjacie, $\mathrm{z}$ rocznym doświadczeniem zawodowym i ukończonym tylko kur- sem A. Obu klinicystów notowało swoje wyniki na odrębnych, wystandaryzowanych kartach badania metody McKenziego dla odcinka lędźwiowego kręgosłupa. Badający nie konsultowali się ze sobą w trakcie wywiadu i badania przedmiotowego ani podczas stawiania diagnozy. Pytania zadawał terapeuta - instruktor. Na kartach zapisywano zgłaszane objawy, obserwacje podczas badania przedmiotowego, diagnozę i zalecenia.

Dodatkowo terapeuta po kursie „A” musiał zapisać swoje zalecenia w rubryce „terapia mechaniczna” zanim instruktor rozpoczął edukację pacjenta na temat jego schorzenia oraz zaleceń. Miało to na celu uniknięcie nanoszenia jakichkolwiek poprawek w stawianej diagnozie i zaleceniach.

\section{Wyniki}

Analiza statystyczna pracy składała się z dwóch etapów. Pierwszym z nich było obliczenie współczynników Kappa dla czterech zmiennych jak: rozpoznanie, kierunek leczniczy, pozycja wyjściowa oraz częstotliwość ćwiczeń. Drugi etap obejmował obliczenie zgodności procentowej wyżej wymienionych zmiennych pomiędzy badającymi (tab.1)

Zmienna rozpoznanie oznacza diagnozę wybraną przez każdego z badających. Klinicyści mieli do wyboru: zespół strukturalny derangement, zespół posturalny, zespół dysfunkcyjny oraz rubrykę inne (rozpoznanie). Zmienna kierunek leczniczy określała rozpoznanie preferencji kierunkowej objawów. Badający wybierali pomiędzy kierunkiem wyprostnym, zgięciowym, dobocznym lub ich kombinacją np. asymetryczny wyprost bądź rotacja $\mathrm{w}$ zgięciu. Zmienna pozycja wyjściowa opisywała pozycję, jaką badający wybrali dla pacjenta do wykonywania zadanych ćwiczeń (np. pozycja stojąca, leżąca), a zmienna częstotliwość ćwiczeń określała jak często pacjenci mają wykonywać ćwiczenia (liczba powtórzeń w ciągu dnia oraz liczba powtórzeń w serii).

Współczynnik Kappa określał stopień zgodności pomiaru tej samej zmiennej w różnych warunkach. W tej pracy miał on wykazać stopień zgodności pomiarów wykonanych przez dwóch testujących. Wartość współczynnika Kappa mieści się w przedziale od -1 do 1 . Wartość 1 oznacza pełną zgodność, wartość 0 oznacza zgodność na poziomie losowego rozkładu danych. Natomiast przedział pomiędzy 0 a $-1 \mathrm{w}$ praktyce nie jest wykorzystywany.

Wyniki analizowanych parametrów przedstawiono w tabeli 1. 
Tab. 1. Zestawienie: zmienna wartość współczynnika Kappa - zgodność procentowa badających

Tab. 1. Summary: variable coefficient Kappa and Interrater reliability in \%

\begin{tabular}{|l|l|l|}
\hline Zmienna/ variable & $\begin{array}{l}\text { Wartość współczynnika Kappa } \\
\text { Kappa coefficient }\end{array}$ & $\begin{array}{l}\text { Zgodność procentowa } \\
\text { Interrater reliability in \% }\end{array}$ \\
\hline Rozpoznanie/ diagnosis & 0,7567 & $75 \%$ \\
\hline Kierunek leczniczy/ directional preference & 1 & $100 \%$ \\
\hline Pozycja wyjściowa/ exercise possition & 1 & $100 \%$ \\
\hline Częstotliwość ćwiczeń/ frequency of exercises & 0,7857 & $78 \%$ \\
\hline
\end{tabular}

\section{Dyskusja}

Uzyskane wyniki badań wskazują, że metoda McKenziego umożliwia minimalizację błędów diagnostycznych, pomimo dużej różnicy w doświadczeniu diagnostów.

W badaniach Werneke i wsp.[12] przeprowadzonych na grupie 1662 pacjentów w wieku od 18 do 91 lat uzyskano nieco inne wyniki. Przedmiotem badań była zgodność diagnoz terapeutów metody McKenziego na poziomach: „A i B”, „C” oraz „D”. Poziom zgodności między terapeutami $\mathrm{w}$ poszczególnych grupach był wyższy niż przewidywano i wynosił 95\%. Pomiędzy grupami natomiast zgodność została opisana, jako niezadowalająca. Autorzy w badaniach wyrazili też potrzebę głębszego zbadania zagadnienia, jakim jest zgodność diagnoz terapeutów na różnych poziomach kształcenia według metody McKenziego.

Kolejne badania autorstwa Werneke i wsp.[13] oceniały zgodność rozpoznania interwencji fizjoterapeutycznych na podstawie wideo i opisów przypadków pacjentów z zespołami bólowymi odcinków lędźwiowego i szyjnego kręgosłupa. Osiągnięto w nich zgodność w przedziałach procentowych od $73 \%$ do $100 \%$.

Badania nad zgodnością systemów diagnostycznych przeprowadzili także Lade i wsp.[14]. Oceniali oni skuteczność i rzetelność badania z użyciem telerehabilitacji $\mathrm{w}$ porównaniu do tradycyjnego badania. Badania prezentowały istotną zgodność dla systemów diagnostycznych na poziomie $73 \%(\mathrm{P}=0.013)$ dla ważności i niemal perfekcyjną zgodność wewnątrz grup badających wynoszącą 90\% ( $\mathrm{P}=0.001)$. Natomiast zgodność i rzetelność pomiędzy grupą badaczy na odległość, a grupą badającą w sposób tradycyjny nie była istotna statycznie i wynosiła $64 \%, \mathrm{P}=0.11$.

W pracy oceniono zgodność diagnoz terapeuty po kursie „A" metody McKenziego z diagnozami instruktora tej metody. Różnice wynikające $\mathrm{z}$ doświadczenia diagnostów istniały przede wszystkim w sytuacjach diagnozowania pacjentów kwalifikujących się do grupy „,inne”. Do grupy ,inne” klasyfikuje się wszystkich pacjentów z podejrzeniem poważnej patologii (z zespołami objawów pod nazwą ,czerwone flagi” oraz pacjentów posiadających schorzenia, których nie można zaliczyć do żadnego z zespołów mechanicznych (np. stenoza) $[15,16]$. Pomimo zaistniałych różnic, zgodność między terapeutami wyniosła od $75 \%$ do $100 \%$. Jest to wynik dobry, biorąc pod uwagę pojawiające się często trudności diagnostyczne i pułapki [17].

Badania nad zgodnością diagnozy w chorobie dyskowej kręgosłupa na podstawie rezonansu magnetycznego prowadzili Truszczyńska i wsp. [18]. Autorzy badali zgodność diagnozy doświadczonego i niedoświadczonego lekarza. Opisali powtarzalność diagnozy od pełnej zgodności na poziomach wyższych do zgodności dobrej i bardzo dobrej na poziomach L4-L5 i L5-S1. Odtwarzalność wyników dotycząca wielkości zmian w krążku międzykręgowym na poziomach Th 12 do L4 wyniosła 0,6, natomiast na poziomach L4-L5 i L5-S1 zgodność była słaba. Powtarzalność wyników wahała się od bardzo dobrej zgodności na poziomie Th12 do L3, do słabej na L3-L4-L5 i średniej na poziomie L5-S1.

Warto również wspomnieć o problematyce leczenia ZBK lędźwiowego. W badaniach własnych odnotowano przypadki, które na podstawie wywiadu i badania przedmiotowego metodą McKenziego zostały zakwalifikowane do interwencji chirurgicznej. W badaniach naukowych poddano pod wątpliwość słuszność interwencji chirurgicznych w obrębie odcinka lędźwiowego kręgosłupa na szeroką skalę. Długofalowe badania autorstwa Kafchitsas i wsp. miały na celu zbadanie zadowolenia, z jakości życia pacjentów 2 lata po leczeniu chirurgicznym odc. L kręgosłupa w porównaniu z pacjentami leczonymi zachowawczo [19]. Do badań użyto skali VAS oraz Wskaźnika Niepełnosprawności ODI. Nie udowodniono wyższości leczenia chirurgicznego nad zachowawczym $(\mathrm{p}<0,01)$.

Potwierdzeniem tego jest prospektywne, kohortowe badanie przeprowadzone przez Svennson'a i wsp. Jego celem była ocena skuteczności leczenia zachowawczego pacjentów z bólami odcinka lędźwiowego kręgosłupa kwalifikującymi się do zabiegu operacyjnego. Terapią, którą zastosowano w badaniu było połączenie Mechanicznego Diagnozowania i Terapii metodą McKenziego oraz ćwiczeń na głęboką stabilizację mięśni tułowia. Do oceny pacjentów użyto kwestionariuszy: ODI (Oswe- 
stry Disability Index), VAS, jak również Europejskiej Skali Jakości Życia. Pacjenci poprawili swoje wyniki we wszystkich kwestionariuszach $(\mathrm{p}<0,001)$ już po 3 miesiącach leczenia [20]. Oba te badania wykazały, iż w wielu przypadkach interwencja chirurgiczna była ostatecznością.

Widać więc, że za pomocą leczenia zachowawczego możliwe jest osiągnięcie zadowalających wyników terapii. Jest to też możliwość ograniczenia wydatków na leczenie związanych z operacją i okresem hospitalizacji.

Przewlekłe bóle kręgosłupa $\mathrm{z}$ roku na rok stają się problemem na coraz większą skalę. Instytuty oraz ośrodki promocji zdrowia podejmują liczne działania w celu znalezienia wystandaryzowanego algorytmu postępowania w przypadku osób z bólami kręgosłupa lędźwiowego [21].

\section{Wartość przeprowadzonych badań}

W przeprowadzonych badaniach zaobserwowano, że pierwszy etap kursu potrafi przygotować terapeutę do samodzielnej pracy z pacjentami cierpiącymi na dolegliwości bólowe odcinka lędźwiowego kręgosłupa. Przedstawiono również sytuacje, kiedy doświadczenie klinicysty jest niezbędne do prawidłowego postawienia diagnozy i rozpoczęcia odpowiedniego leczenia (25\% badanych).

\section{Ograniczenia przeprowadzonych badań}

Badania przeprowadzono na nielicznej grupie chorych, co niewątpliwie należy do ograniczeń przeprowadzonych badań. Kolejnym ograniczeniem była rola obserwatora terapeuty po kursie „A”. Nasuwa to pytanie czy w przypadku samodzielnego zadawania pytań w trakcie wywiadu, jak również samodzielnej oceny mechanicznej początkujący terapeuta postąpiłby tak samo jak instruktor. Nie było możliwości innego sposobu zaprojektowania badań, a wiec zastosowania zaślepienia pojedynczego bądź podwójnego. Badania w realnych warunkach to uniemożliwiają.

W przypadku przeprowadzania badania z samodzielną oceną terapeuty po kursie „A” ci sami pacjenci musieli by być badani dwukrotnie a to rodzi wątpliwości czy ten sam pacjent umiałby opisać swoje objawy powtórnie. W przypadkach niektórych pacjentów powtórne testowanie mechaniczne mogłoby również zadziałać na ich szkodę.

Kolejną kwestią są pacjenci z tzw. „żółtymi flagami”, czyli pacjenci, którzy w większości nastręczają swoistych trudności zarówno w wywiadzie jak i w edukacji oraz omawianiu zaleceń terapeutycznych nie stanowili wyzwania dla instruktora. Nieco inaczej sytuacja przedstawiała się $\mathrm{w}$ wypadku młodego terapeuty. W pracy z wyżej wymienionymi pacjentami wymaga się od terapeuty stanowczości, opanowania i pewności siebie, które również wynikają niejako z doświadczenia zawodowego.
Kolejnym problem relacji terapeuta - pacjent w tym wypadku stanowi autorytet instruktora metody, który jest polecanym i uznawanym w środowisku specjalistą. Terapeuta po kursie A natomiast ze względu na młody wiek spotyka się często w praktyce klinicznej z początkową rezerwą i nieufnością pacjentów, co do jego kompetencji. Istotną kwestią, którą warto poruszyć na koniec tych rozważań jest proces uczenia się terapeuty - słuchacza podczas przeprowadzania każdego kolejnego badania podmiotowego i przedmiotowego co w efekcie pozwala na stawianie przez niego coraz trafniejszych diagnoz.

\section{Wnioski}

1. Kurs „A” metody McKenziego, pozwala przygotować terapeutę do diagnostyki i planowania terapii pacjentów z bólami kręgosłupa lędźwiowego w przebiegu choroby dyskowej.

2. Metoda McKenziego umożliwiła ograniczenie najważniejszych błędów diagnostycznych u niedoświadczonego terapeuty.

3. Różnice wynikające $z$ doświadczenia diagnostów istniały przede wszystkim w sytuacjach diagnozowania pacjentów kwalifikujących się do grupy ,inne”.

\section{Piśmiennictwo}

1. McKenzie R, May S. Mechanical diagnosis and therapy. Second ed. Waikanae, Spinal Publication New Zeland Ltd; 2003.

2. Waxman R, Tennant A, Helliwell P. A prospective follow-up study of low back pain in the community. Spine 2000;25(16):2085-90.

3. Weber M. Back pain in emergency setting. Ther Umsch 2013;70(9):503-8.

4. Altaf F, Heran MK, Wilson LF. Back pain in children and adolescence. Bone Joint J 2014;96-B(6):717-23.

5. Taxter AJ, Chauvin NA, Weiss PF. Diagnostic and treatment in paediatric population. Phys Sportsmed 2014;42(1):94-104.

6. Stan zdrowia ludności Polski w 2009 r. Główny Urząd Statystyczny. Warszawa, 2011.

7. Dunn KM, Hestbaek L, Cassidy JD. Low back pain across the life course. Best Pract Res Clin Rheumatol 2013;27(5):591-600.

8. Klipstein A, Nydegger A. Back pain In the working age population, Ther Umsch 2013;70(9):515-21.

9. Hasler C. Back pain during growth. Swiss Med Wkly 2013;143.

10. Slipman CW, Patel RK, Botwin K, Huston C, Zhang L, Lenrow D, Garvan C. Epidemiology of spine tumors presenting to musculoskeletal Physiatrists. Archives of Physical Medicine and Rehabilitation 2003;84: 492-5. 
11. Deyo RA, Rainville J, Kent D. What can history and physical examination tell us about low back pain? JAMA 1992;268;70-765.

12. Werneke MW, Deutscher D, Hart DL, Stratford P, Ladin J, Weinberg J, Herbowy S, Resnik L. McKenzie lumbar classification: inter-rater agreement by physical therapists with different levels of formal McKenzie postgraduate training, Spine 2014;39(3):E182-90.

13. Werneke MW, Hart DL, Deutscher D, Stratford PW. Clinician's ability to identify neck and low back interventions: an inter-rater chance-corrected agreement pilot study. J Man Manip Ther 2011;19(3):172-81.

14. Lade H, McKenzie S, Steele L, Russel T. Validity and reliability of the assessment and diagnosis of musculoskeletal elbow disorders using telerehabilitation. J Telemed Telecare 2012;18(7):413-8.

15. Truszczyńska A. Wartość badania wg McKenziego w diagnostyce klinicznej bólów kręgosłupa w przebiegu infekcyjnych zapaleń i przerzutów nowotworowych. Chir.Narz. Ruchu i Ortop Pol 2011:339-343.

16. Greenhalgh S, Selfe J. Red flags: a guide to identifying serious pathology of spine. Churchill Livingstone Elsevier 2006.
17. Rąpała K, Walczak P, Truszczyńska A, Łukawski S, Nowak-Misiak M. Problemy diagnostyczne i terapeutyczne zespołów bólowych kręgosłupa i ich podział wg kolorowych flag. Ortop Traumatol Rehabil 2012;3:215-228.

18. Truszczyńska A, Brychcy A, Rąpała K, Walczak P, Truszczyński O, Tarnowski A. Powtarzalność i odtwarzalność wyników oceny rezonansu magnetycznego kręgosłupa lędźwiowego u kandydatów na pilotów samolotów. Ortop Traumatol Rehabil 2011;13(4):343-351.

19. Kafchitsas K, Habermann B, Khan F, Matzaroglou C. Operations in spinal surgery are not always needed. Do we operate more than we should. Hell J Nucl Med 2014;17(1):17-9.

20. Svensson GL, Wendt GK, Thomeé R. A structured physiotherapy treatment model can provide rapid relief to patients who qualify for lumbar disc surgery: a prospective cohort study. J Rehabil Med 2014;46(3):233-40.

21. Deyo RA, Dworkin SF, Amtmann D. Report of the national institutes of health task force on research standards for chronic low back pain. J Manipulative Physiol Ther 2014;37(7):449-67. 